\title{
Has the Genetic Contribution to the Propensity to Gamble Increased? Evidence From National Twin Studies Conducted in 1962 and 2002
}

\author{
Wendy S. Slutske \\ Department of Psychological Sciences, University of Missouri, Columbia, MO, USA
}

\begin{abstract}
Social changes, such as the expansion of legal forms of gambling, can influence not only the prevalence of gambling, but can also shape the relative importance of genetic and environmental contributions to individual differences in the propensity to gamble. In the present study, I examined differences in the prevalence and in the relative contribution of genetic and environmental factors to gambling involvement in the United States in 1962 versus 2002. The data came from two sources: (1) a survey of 839 17-year-old same-sex twin pairs from the National Merit Scholarship Qualifying Test twin study, and (2) an interview of 477 18- to 26year-old same-sex twin pairs from Wave III of the National Longitudinal Study of Adolescent to Adult Health. Similar measures of gambling participation were included in the two studies. Evidence for a genotype-bytime interaction was evaluated by testing whether the contribution of genetic influences was greater in the more recently born cohort of twins. Despite the major changes in the gambling landscape over the intervening 40 years, there was no evidence for such an interaction. The contribution of genetic factors and environmental factors did not significantly differ and there was no evidence for genetic influences at either time point. Instead, the variation in the propensity to gamble was explained nearly equally by common and unique environmental factors. Explanations for this surprising finding are discussed.
\end{abstract}

Keywords: gambling, twins, birth cohort, gene by environment interaction

There have been massive changes in the availability of legal gambling opportunities in the United States over the last half century (Tidwell et al., 2015). Coinciding with this increased availability have been increases in the prevalence of gambling involvement and disorder (Gerstein et al., 1999; Kessler et al., 2008; Shaffer \& Hall, 2001; Welte et al., 2011), and a decrease in the average age of gambling initiation (Richmond-Rakerd et al., 2013).

Social changes, such as the expansion of legal forms of gambling, can influence not only the prevalence of a behavior, but can also shape the relative importance of genetic and environmental contributions to individual differences in the behavior. Cigarette smoking provides the best example. Cigarettes became much more widely available early in the 20th century with the invention of automatic cigarette rolling machines and safety matches, and a rise in product marketing (Cummings \& Proctor, 2014). This led to an increase in the prevalence of cigarette smoking in the United States from essentially zero in 1900 to $42 \%$ by 1963 (Burns et al., 1997). In the latter half of the 20th century, a series of public health events, including the pivotal Surgeon General's report on smoking and health in 1964
(Burns et al., 1997; U.S. Department of Health and Human Services, 2014), marked the beginning of a decline in the prevalence of smoking to 15\% in 2015 (King et al., 2016).

Just as changes in availability and public health policies affected the prevalence of smoking, they also appear to have affected the extent to which individual differences were due to genetic or environmental influences. For example, an examination of birth cohort differences in the heritability of smoking in a national U.S. twin sample yielded striking differences in the heritability of smoking among those who came of age prior to 1964 when cigarettes were cheap, plentiful, socially acceptable, and not yet considered a health risk $\left(h^{2}=\sim 60 \%\right)$ compared to those who came of age around the time that the Surgeon General's report was released ( $h^{2}=\sim 0$; Boardman et al., 2010). A

RECEIVED 1 February 2018; ACCEPTED 5 February 2018. First published online 12 March 2018.

ADDRESS FOR CORRESPONDENCE: Professor Wendy S. Slutske, Department of Psychological Sciences, University of Missouri, Columbia, MO 65211, USA. E-mail: slutskew@missouri.edu 
similar phenomenon was observed in Swedish and Spanish twin studies that showed that as the prevalence of smoking among women in more recently born birth cohorts increased, the heritability also increased, both presumably due to increasing social acceptability of smoking in women (Kendler et al., 2000; Mezquita et al., 2018). These changes in heritability observed in different birth cohorts are examples of a phenomenon that might be termed genotype-bytime interaction-a genotype-by-environment interaction (Shanahan \& Hofer, 2005) where the relevant environment is change occurring across historical periods.

Several theories of the mechanisms underlying the genotype-by-time interaction have been proposed (Boardman et al., 2010). The social control model posits that genetic differences are dampened over time by social forces (Shanahan \& Hofer, 2005), whereas the social trigger model suggests that genetic differences are amplified over time by social forces. For example, the rise in the heritability of smoking prior to the Surgeon General's report in the United States (and among women in Sweden and Spain) could be explained by a social trigger model, and the declining heritability of smoking after the report is consistent with the social control model. A third model, a social push model, asserts that genetic differences may be hidden or highlighted by changing social forces. This model provides an explanation for the increasing heritability of smoking in the decades since the Surgeon General's report (Boardman et al., 2010). The population of smokers that remained may have shifted to those who were more genetically vulnerable to nicotine addiction (Boardman et al., 2011; Emery et al., 2000; Hughes, 2011).

There are some parallels in the rising popularity and prevalence of gambling in the latter half of the 20th century (Volberg et al, 1999) to smoking in the first half (Brandt, 2007) in the United States. This raises the question of whether there may also be parallels in the contribution of genetic factors to individual differences among cohorts born during different historical periods. This question was the focus of the present study. The genetic and environmental contributions to gambling were examined in two distinct birth cohorts born around 1945 and 1980. Gambling involvement in the two cohorts was assessed around 1962 and 2002. In 1962, the United States was still going through a period of gambling prohibition, there were no legal lotteries in the United States, and the only casinos were in Nevada. In 2002, there was legal gambling in nearly every state, including lotteries in 41 states and casinos in 30. I hypothesized that, based on predictions of the social trigger model, the prevalence and heritability of gambling would be higher in the 2002 than in the 1962 cohort.

\section{Methods}

\section{Participants}

Secondary analyses were conducted of data from two national samples of young people, the National Merit Schol- arship Qualifying Test twin study and the National Longitudinal Study of Adolescent to Adult Health.

National Merit Scholarship Qualifying Test twin study (National Merit). This is a sample of same-sex twin pairs who participated in the 1962 National Merit Scholarship Qualifying Test (Loehlin \& Nichols, 1976). Twin pairs were identified from 596,241 high school juniors who completed the test; 1,507 same-sex twin pairs were recruited to respond to further questionnaires about personality and behavior. Participation rates were very good (79\%). Among the respondents were 509 monozygotic (MZ) and 330 same-sex dizygotic (DZ) twin pairs. Participants were approximately 17-years old at the time of the test administration and the sample was overwhelmingly (98\%) Caucasian, with females being slightly over-represented (58\%). A previous paper (Slutske et al., 2009) included summary statistics of the individual gambling behaviors in this cohort that were extracted from the original source (Loehlin \& Nichols, 1976). The raw data were subsequently obtained, which made this new set of analyses possible.

National Longitudinal Study of Adolescent to Adult Health (Add Health). This sample is from the Wave III in-home interview of the National Longitudinal Study of Adolescent to Adult Health, which took place in 2001-2002 and included an assessment of gambling. The Add Health study included a genetically informative subsample of twins and siblings (Harris et al., 2006). To be consistent with the National Merit twin study, only data from the 220 complete (and 35 partial) MZ and 182 complete (and 40 partial) same-sex DZ twin pairs were used in this analysis. The twin pairs in this national sample came from 45 different states and $87 \%$ of the pairs lived in the same state. Participant response rates at Wave III for the genetic sample were excellent (92\% for MZ twins and $89 \%$ for DZ twins). All participants gave informed consent and the study was approved by the Institutional Review Board of the University of North Carolina at Chapel Hill. These data have previously been published (Slutske \& Richmond-Rakerd, 2014), but not in the context of an investigation of a cross-cohort genotype-by-time interaction.

\section{Measures}

Both studies included assessments of the most common gambling activities of the time. Included in the National Merit survey were four questions about the frequency of participation in gambling (frequently, occasionally, or not at all) in the past year. The first two response options were combined to harmonize the assessments between the two samples (and because the endorsement of 'frequently' was rare). Included in the Add Health interview were eight questions about gambling, with the first three questions about ever participating in three different types of gambling activities (Slutske \& Richmond-Rakerd, 2014). With the 


\section{TABLE 1}

Assessment and Prevalence of Gambling Behaviors in the Two Cohorts

\begin{tabular}{|c|c|c|c|c|c|}
\hline \multicolumn{3}{|l|}{1962 - National Merit } & \multicolumn{3}{|l|}{2002 - Add Health } \\
\hline \multirow[b]{2}{*}{ Gambling behavior } & \multicolumn{2}{|c|}{ Prevalence } & \multirow[b]{2}{*}{ Gambling behavior } & \multicolumn{2}{|c|}{ Prevalence } \\
\hline & M & W & & M & W \\
\hline Not Yet Available & - & - & Bought lottery tickets, such as daily, scratch-offs, or lotto & 62.1 & 57.1 \\
\hline Played a slot machine & 11.0 & 11.2 & $\begin{array}{l}\text { Played casino tables or video games for money-such } \\
\text { games as craps, blackjack, roulette, slot machines, or } \\
\text { video poker }\end{array}$ & 52.2 & 42.3 \\
\hline Gambled with cards & 47.5 & 17.3 & & & \\
\hline $\begin{array}{l}\text { Made bets on a game or } \\
\text { other event }\end{array}$ & 45.8 & 22.0 & $\begin{array}{l}\text { Played any other games, such as cards or bingo, for } \\
\text { money, or bet on horse races or sporting events, or } \\
\text { taken part in any other kinds of gambling for money }\end{array}$ & 47.8 & 30.1 \\
\hline Gambled with dice & 12.9 & 03.5 & & & \\
\hline Any gambling & 65.2 & 37.9 & Any gambling & 76.7 & 69.7 \\
\hline
\end{tabular}

exception of playing the lottery, which was not yet legal in the United States at the time of the National Merit study, there was considerable overlap between the two assessments (see Table 1). The gambling items were combined into a single 'any gambling' outcome in the two studies.

\section{Data Analysis}

The frequencies of any gambling in the two samples and among men and women were compared using survey data analysis procedures in SAS version 9.4 (SAS Institute Inc., Cary, NC) that take into account the non-independence of twin pair observations.

Biometric models were fitted using robust weighted least squares directly to the raw twin data using Mplus Version 7 (Muthén and Muthén, 2012). To account for the age differences in the two cohorts, models included age as a covariate. Univariate biometric model fitting was conducted to partition the variation in the propensity to gamble into additive genetic (A), shared environmental (C), and unique environmental (E) influences, and to test for cohort differences in the genetic and environmental contributions to gambling liability (Prescott, 2004; Rijsdijk \& Sham, 2002). Evidence for cohort differences was tested by comparing the fits of models that allowed parameter estimates for the National Merit 1962 and Add Health 2002 cohorts to vary with the fits of models that constrained the estimates to be the same. Evidence for sex differences was similarly tested by comparing the fits of models that allowed parameter estimates for the men and women to vary with the fits of models that constrained the estimates to be the same.

\section{Results}

\section{Prevalences}

The prevalence of gambling in 2002 was significantly higher than in 1962 in the full sample (75\% vs. 49\%; odds ratio $\left.[O R]=2.80 ; \chi^{2}=103.35, d f=1, p<.0001\right)$, among men $\left(O R=1.75 ; \chi^{2}=12.91, d f=1, p=.0003\right)$ and women $(O R$ $\left.=3.76 ; \chi^{2}=97.90, d f=1, p<.0001\right)$. In both the 1962 $\left(O R=3.07 ; \chi^{2}=90.78, d f=1, p<.0001\right)$ and $2002(O R$ $\left.=1.43 ; \chi^{2}=4.26, d f=1, p=.039\right)$ cohorts, the prevalence of gambling was higher among men than among women (see Table 1). When the 2002 cohort was restricted to a sample closer in age (18-19 years of age) to the 1962 cohort, the prevalences of gambling among men $(68 \%)$ and women (55\%) decreased and the differences between the two cohorts were attenuated. This suggests that the differences in prevalences were due to age as well as birth cohort effects.

\section{Biometric Model Fitting}

A model that allowed the contribution of genetic and environmental influences to the propensity to gamble to differ in the two cohorts did not fit significantly better than a model that constrained the contributions to be equivalent $\left(\Delta \chi^{2}=1.01, d f=2, p=.60\right)$. In both the $1962\left(\Delta \chi^{2}=\right.$ $0.71, d f=2, p=.70)$ and the 2002 cohorts $\left(\Delta \chi^{2}=0.05, d f\right.$ $=2, p=.97)$, the contribution of genetic and environmental influences to the propensity to gamble did not significantly differ in men and women. In the models that constrained the parameter estimates in men and women, there was evidence that the shared and unique environment, but not genetic factors, significantly contributed to the propensity to gamble in both cohorts (see Table 2).

\section{Discussion}

Based on compelling findings from the smoking literature, I examined the prevalence and genetic and environmental contributions to the propensity to gamble in two distinct birth cohorts born around 1945 and 1980. As expected, the prevalence of any gambling increased, from $49 \%$ among those born around 1945 (in 1962) to 75\% among those born around 1980 (in 2002). Interestingly, the first U.S. national gambling prevalence survey was conducted 13 years after the National Merit twin study, at which point there were still 


\begin{tabular}{|c|c|c|c|c|c|c|c|}
\hline \multicolumn{8}{|c|}{$\begin{array}{l}\text { Proportion of Variation in Any Gambling Explained by Additive (A), Shared Environmental (C), and Unique } \\
\text { Environmental (E) Influences Among Young People in } 1962 \text { Versus } 2002\end{array}$} \\
\hline \multirow[b]{2}{*}{ Cohort } & & \multicolumn{3}{|c|}{ Men } & \multicolumn{3}{|c|}{ Women } \\
\hline & & A & C & E & A & C & $\mathrm{E}$ \\
\hline \multirow[t]{4}{*}{1962 - National Merit } & Full model & 0.02 & 0.59 & 0.39 & 0.26 & 0.32 & 0.42 \\
\hline & $95 \% \mathrm{Cl}$ & $-0.49,0.53$ & $0.17,1.02$ & $0.23,0.55$ & $-0.22,0.73$ & $-0.09,0.73$ & $0.28,0.55$ \\
\hline & $\mathrm{M}=\mathrm{W}$ model & 0.14 & 0.46 & 0.41 & 0.14 & 0.46 & 0.41 \\
\hline & $95 \% \mathrm{Cl}$ & $-0.21,0.48$ & $0.16,0.75$ & $0.30,0.51$ & $-0.21,0.48$ & $0.16,0.75$ & $0.30,0.51$ \\
\hline \multirow[t]{4}{*}{2002 - Add Health } & Full model & 0.00 & 0.45 & 0.55 & 0.00 & 0.54 & 0.46 \\
\hline & $95 \% \mathrm{Cl}$ & $-0.88,0.88$ & $-0.27,1.16$ & $0.26,0.85$ & $-0.74,0.74$ & $-0.04,1.13$ & $0.20,0.71$ \\
\hline & $\mathrm{M}=\mathrm{W}$ model & 0.00 & 0.50 & 0.50 & 0.00 & 0.50 & 0.50 \\
\hline & $95 \% \mathrm{Cl}$ & $0.00,0.00$ & $0.36,0.64$ & $0.36,0.64$ & $0.00,0.00$ & $0.36,0.64$ & $0.36,0.64$ \\
\hline
\end{tabular}

Note: $\mathrm{A}=$ additive genetic influences, $\mathrm{C}=$ shared environmental influences, $\mathrm{E}=$ unique environmental influences, $\mathrm{Cl}=\mathrm{confidence}$ interval. Parameters in bold are significantly greater than zero at $p<.05$.

casinos in only one state, but legal lotteries in 12 ; the prevalence of any gambling had reached $73 \%{ }^{1}$ among $18-24$ year olds (Kallick et al., 1979).

Contrary to predictions based on the social trigger model, there were no differences in the genetic contribution to gambling propensity across these two historical periods. In fact, in both the 1962 National Merit sample and the 2002 Add Health sample, all of the variation in the propensity to gamble was due to environmental factors, including those environmental factors that are shared between members of the same family and those that are unique to the individual. What makes these consistent findings so remarkable is that the gambling participation in 1962 was primarily non-commercial or illegal, whereas in 2002 it was primarily commercial and legal.

Another puzzling aspect of these results is that they are not in line with the two previous twin studies that focused on gambling among young people. In a study of 279 13-year-old Quebec twin pairs, gambling involvement was completely explained by genetic and unique environmental factors, with no contribution from the shared family environment (Vitaro et al., 2014). A study of 756 Minnesota twin pairs assessed at ages 18 and 25 years reported results for several measures of gambling, including one 'typical frequency' similar to the measure used in the Quebec study (King et al., 2017). ${ }^{2}$ In the Minnesota study, there were significant genetic influences on variation in typical frequency at ages 18 and 25 years. There was a substantial and significant contribution of the shared environment only at age 18 years (King et al., 2017).

One potential explanation for the discrepant findings of the present and the two prior studies might be that the measures focused on different stages of gambling. The present study focused on whether the participant had gambled or not (either in the past year or ever), which is similar to the concept of initiation used in the substance use literature. Initiation is the milestone in the gambling career when one transitions from being a non-gambler to a gambler. Once gambling has been initiated, gamblers can be differentiated on a number of characteristics, such as how frequently they gamble or whether they develop problems as a consequence of their gambling. The previous studies focused on a composite indicator of gambling that included initiation and the average frequency of participating in different types of gambling. Based on findings from the substance use literature demonstrating that the contribution of genetic influences increase and the contribution of shared environmental influences decrease with the stage of substance use involvement (Fowler et al., 2007; Pagan et al., 2006; Rhee et al., 2003), it has been suggested that genetic factors may play an increasing role and shared environmental factors a decreasing role at later stages of gambling involvement progression (i.e., from initiation to frequency of use to disordered gambling; Slutske, in press; Slutske \& Richmond-Rakerd, 2014). In other words, whether one gambles at all is primarily due to the environment; how or how much one gambles is also due to genes.

Another explanation might reside with the composition of the samples. The present study was based on national twin samples, whereas the two previous studies were based on regional twin samples. Although the shared environment is often assumed to be a feature specific to the family, especially in national samples such as the National Merit and Add Health twin samples, 'place' is an important aspect of the shared environment. (Of course, place would also potentially be an important aspect of the unique environment in adult twin samples-that is, twins might move apart once they reach adulthood.) This is particularly true for gambling in the United States because it is regulated at the state level. Thus, observing substantial contributions of the shared environment in the National Merit and Add Health twin studies, but weaker contributions in the Minnesota and Quebec twin studies, may be explained by geographic differences contributing to differences between families (that are shared by the members of twins residing in the same state). This is consistent with evidence from national studies documenting associations between the number of legal gambling activities in one's state and the prevalence of gambling, gambling frequently, or of having a gambling disorder (Kallick et al., 1979; Welte et al., 2016); 
the number of legal gambling activities even increased the prevalence of participating in illegal gambling activities in the 1975 national survey (Kallick et al., 1979). In sum, the state where one lives is a strong contributor to individual differences in gambling involvement and it is shared by adolescent twin pairs.

The fundamental issue is that estimates of genetic and environmental influences are a function of the overall variation in a trait (in a specific population at a given time). The overall variation is composed of genetic and environmental portions. Greater environmental variability will lead to a proportionately greater contribution to the overall variability in a population, and changes in the amount of environmental variability will change the estimates of both genetic and environmental influences. The thesis here is that there will be greater environmental variability in a national U.S. twin sample than a regional twin sample, and that this will be reflected in a greater contribution of environmental influences in the former than the latter.

Although it is not possible to adjudicate between the 'stage' and the 'place' explanations of the different study findings, it appears that they are at least as important as 'time' when trying to understand contributions to individual differences in gambling. With respect to the issue of 'place', it is likely that in a national U.S. sample of adolescent twins all living together in the same state, the profound influence of environmental variation will mask any genetic contributions to the propensity to gamble. When one hones in on contexts with less environmental variation, the influence of genetic factors may 'shine through' (Boardman et al., 2010; Raine, 2002).

\section{Limitations}

The main limitation of this study was that the ages of the samples differed-the participants in the National Merit sample were all approximately 17 years old, the participants in the Add Health sample were 18-26 years of age. Thus, the differences in prevalences may have been due to age as well as birth cohort effects. However, there is no plausible explanation of how failure to find cohort differences in the proportions of variation in the propensity to gamble attributable to genetic and environmental factors could be due to age differences between the two samples. In other words, the main finding of this study is unaffected by the age differences between the two cohorts.

\section{Conclusions}

There was no evidence to support the social trigger model of gene-by-time interaction in the propensity to gamble among young people. Rather, given the similar findings in 1962 and 2002, it is possible that the genetic contributions to gambling propensity were being masked by environmental cross-state differences in the United States that existed in 1962 and that still existed in 2002. ${ }^{3}$ Especially when inter- preting findings of behavioral genetic studies of gambling (or other activities for which regulations vary across jurisdictions, such as marijuana use, e.g., Azofeifa et al., 2018), the varied and changing landscape of gambling over time and place must always be considered. The increasing popularity of online gambling (Welte et al., 2015), delivered directly to nearly anywhere in the world via mobile technologies, may eventually level the gambling landscape in the coming years. It is hypothesized that such a leveling of the gambling landscape would alter the relative contributions of genetic and environmental factors to gambling involvement in national U.S. twin studies.

\section{Acknowledgments}

Preparation of this manuscript was supported in part by a Center of Excellence grant from the National Center for Responsible Gaming. The research uses data from Add Health, a program project directed by Kathleen Mullan Harris and designed by J. Richard Udry, Peter S. Bearman, and Kathleen Mullan Harris at the University of North Carolina at Chapel Hill, and funded by grant P01-HD31921 from the Eunice Kennedy Shriver National Institute of Child Health and Human Development, with cooperative funding from 23 other federal agencies and foundations. Special acknowledgment is due to Ronald R. Rindfuss and Barbara Entwisle for assistance in the original design. Information on how to obtain the Add Health data files is available on the Add Health website (http://www.cpc.unc.edu/addhealth). No direct support was received from grant P01-HD31921 for this analysis. The author also expresses gratitude to John Loehlin and Robert Nichols for having the foresight to assess gambling behavior in their landmark study. None of the authors have any conflicts of interest to report.

\section{Endnotes}

1 Based on a more comprehensive assessment of gambling than used in the present study.

2 This entailed averaging the frequency of participation in 10 (King et al., 2017) or 12 (Vitaro et al., 2014) different gambling activities over the past 12 months, with past-year non-gamblers coded as zero. This measure taps into several components-gambling versatility, frequency, and initiation.

3 A misconception held by some is that only problematic outcomes such as 'gambling addiction' can be influenced by genes, and that leisure activities such as gambling participation cannot. This runs contrary to a vast behavioral genetic literature documenting heritable influences on nearly every human behavioral trait studied (Plomin et al., 2016; Turkheimer, 2000).

\section{References}

Azofeifa, A., Sherman, L. J., Mattson, M. E., \& Pacula, R. L. (2018). Marijuana buyers in the United States, 2010-2014. Drug and Alcohol Dependence, 183, 34-42. 
Boardman, J. D., Blalock, C. L., \& Pampel, F. C. (2010). Trends in the genetic influences on smoking. Journal of Health and Social Behavior, 51, 108-123.

Boardman, J. D., Blalock, C. L., Pampel, F. C., Hatemi, P. K., Heath, A. C., \& Eaves, L. J. (2011). Population composition, public policy, and the genetics of smoking. Demography, 48, $1517-1533$.

Brandt, A. M. (2007). The cigarette century: The rise, fall, and deadly persistence of the product that defined America. New York, NY: Basic Books.

Burns, D. M., Lee, L., Shen, L. Z., Gilpin, E., Tolley, H. D., Vaughn, J., \& Shanks, T. G. (1997). Cigarette smoking behavior in the United States. Changes in cigarette-related disease risks and their implication for prevention and control. Smoking and Tobacco Control Monograph, 8, 13-42.

Cummings, K. M., \& Proctor, R. N. (2014). The changing public image of smoking in the United States: 1964-2014. Cancer Epidemiology and Prevention Biomarkers, 23, 32-36.

Emery, S., Gilpin, E. A., Ake, C., Farkas, A. J., \& Pierce, J. P. (2000). Characterizing and identifying 'hard-core' smokers: Implications for further reducing smoking prevalence. American Journal of Public Health, 90, 387-394.

Fowler, T., Lifford, K., Shelton, K., Rice, F., Thapar, A., Neale, M. C., ... van den Bree, M. B. (2007). Exploring the relationship between genetic and environmental influences on initiation and progression of substance use. Addiction, 102, 413-422.

Gerstein, D. R., Volberg, R. A., Toce, M. T., Harwood, H., Christiansen, E. M., Hoffman, J., ... Hill, M. A. (1999). Gambling impact and behavior study: Report to the national gambling impact study commission. Chicago, IL: National Opinion Research Center, University of Chicago.

Harris, K. M., Halpern, C. T., Smolen, A., \& Haberstick, B. C. (2006). The national longitudinal study of adolescent health (Add Health) twin data. Twin Research and Human Genetics, 9, 988-997.

Hughes, J. R. (2011). The hardening hypothesis: Is the ability to quit decreasing due to increasing nicotine dependence? A review and commentary. Drug and Alcohol Dependence, 117, 111-117.

Kallick, M. D., Suits, T., Dielman, T., \& Hybels, J. (1979). A survey of American gambling attitudes and behavior (Research Report Series). Ann Arbor: Survey Research Center, Institute for Social Research, University of Michigan Press.

Kendler, K. S., Thornton, L. M., \& Pedersen, N. L. (2000). Tobacco consumption in Swedish twins reared apart and reared together. Archives of General Psychiatry, 57, 886-892.

Kessler, R. C., Hwang, I., LaBrie, R., Petukhova, M., Sampson, N. A., Winters, K. C., \& Shaffer, H. J. (2008). The prevalence and correlates of DSM-IV pathological gambling in the national comorbidity survey replication. Psychological Medicine, 38, 1351-1360.

King, J. A., Neff, L. J., Whitmill, J., Babb, S. D., \& Graffunder, C. M. (2016). Current cigarette smoking among adultsUnited States, 2005-2015. Morbidity and Mortality Weekly Report, 65, 1205-1211.
King, S. M., Keyes, M., Winters, K. C., McGue, M., \& Iacono, W. G. (2017). Genetic and environmental origins of gambling behaviors from ages 18 to 25: A longitudinal twin family study. Psychology of Addictive Behaviors, 31, 367-374.

Loehlin, J. C., \& Nichols, R. C. (1976). Heredity, environment, and personality: A study of 850 sets of twins. Austin, TX: University of Texas Press.

Mezquita, L., Sánchez-Romera, J. F., Ibáñez, M. I., Morosoli, J. J., Colodro-Conde, L., Ortet, G., \& Ordoñana, J. R. (2018). Effects of social attitude change on smoking heritability. Behavior Genetics, 48, 12-21.

Muthén, L. K., \& Muthén, B. O. (2012). Mplus user's guide (7th ed.). Los Angeles, CA: Author.

Pagan, J. L., Rose, R. J., Viken, R. J., Pulkken, L., Kaprio, J., \& Dick, D. M. (2006). Genetic and environmental influences on stages of alcohol use across adolescence and into young adulthood. Behavior Genetics, 36, 483-497.

Plomin, R., DeFries, J. C., Knopik, V. S., \& Neiderhiser, J. M. (2016). Top 10 replicated findings from behavioral genetics. Perspectives on Psychological Science, 11, 3-23.

Prescott, C. A. (2004). Using the Mplus computer program to estimate models for continuous and categorical data from twins. Behavior Genetics, 34, 17-40.

Raine, A. (2002). Biosocial studies of antisocial and violent behavior in children and adults: A review. Journal of Abnormal Child Psychology, 30, 311-326.

Rhee, S. H., Hewitt, J. K., Young, S. E., Corley, R. P., Crowley, T. J., \& Stallings, M. C. (2003). Genetic and environmental influences on substance initiation, use, and problem use in adolescents. Archives of General Psychiatry, 60, 1256-1264.

Richmond-Rakerd, L. S., Slutske, W. S., \& Piasecki, T. M. (2013). Birth cohort and sex differences in the age of gambling initiation in the United States: Evidence from the national comorbidity survey replication. International Gambling Studies, 13, 417-429.

Rijsdijk, F. V., \& Sham, P. C. (2002). Analytic approaches to twin data using structural equation models. Briefings in Bioinformatics, 3, 119-133.

Shaffer, H. J., \& Hall, M. N. (2001). Updating and refining prevalence estimates of disordered gambling behaviour in the United States and Canada. Canadian Journal of Public Health, 92, 168-172.

Shanahan, M. J., \& Hofer, S. M. (2005). Social context in geneenvironment interactions: Retrospect and prospect. The Journals of Gerontology Series B: Psychological Sciences and Social Sciences, 60, 65-76.

Slutske, W. S. (in press). Genetic and environmental contributions to risk for disordered gambling. In A. Heinz, N. Romanczuk-Seiferth, \& M. Potenza ( Eds.), Gambling disorder. Springer.

Slutske, W. S., \& Richmond-Rakerd, L. S. (2014). A closer look at the evidence for sex differences in the genetic and environmental influences on gambling in the national longitudinal study of adolescent health: From disordered to ordered gambling. Addiction, 109, 120-127. 
Slutske, W. S., Meier, M. H., Zhu, G., Statham, D. J., Blaszczynski, A., \& Martin, N. G. (2009). The Australian twin study of gambling (OZ-GAM): Rationale, sample description, predictors of participation, and a first look at sources of individual differences in gambling involvement. Twin Research and Human Genetics, 12, 63-78.

Tidwell, M. C. O., Welte, J. W., Barnes, G. M., \& Dayanim, B. (2015). Gambling modes and state gambling laws: Changes from 1999 to 2011 and beyond. Gaming Law Review and Economics, 19, 13-26.

Turkheimer, E. (2000). Three laws of behavior genetics and what they mean. Current Directions in Psychological Science, 9, 160-164.

U.S. Department of Health and Human Services. (2014). The health consequences of smoking: 50 years of progress. A report of the Surgeon General. Atlanta, GA: U.S. Department of Health and Human Services, Centers for Disease Control and Prevention, National Center for Chronic Disease Prevention and Health Promotion, Office on Smoking and Health.
Vitaro, F., Hartl, A. C., Brendgen, M., Laursen, B., Dionne, G., \& Boivin, M. (2014). Genetic and environmental influences on gambling and substance use in early adolescence. Behavior Genetics, 44, 347-355.

Volberg, R. A., Toce, M. T., \& Gerstein, D. R. (1999). From back room to living room: Changing attitudes toward gambling. Public Perspective, 10, 8-13.

Welte, J. W., Barnes, G. M., Tidwell, M. C. O., \& Hoffman, J. H. (2011). Gambling and problem gambling across the lifespan. Journal of Gambling Studies, 27, 49-61.

Welte, J. W., Barnes, G. M., Tidwell, M. C. O., Hoffman, J. H., \& Wieczorek, W. F. (2015). Gambling and problem gambling in the United States: Changes between 1999 and 2013. Journal of Gambling Studies, 31, 695-715.

Welte, J. W., Tidwell, M. C. O., Barnes, G. M., Hoffman, J. H., \& Wieczorek, W. F. (2016). The relationship between the number of types of legal gambling and the rates of gambling behaviors and problems across US states. Journal of Gambling Studies, 32, 379-390. 